\title{
Origem e dinâmica da deposição dos sedimentos superficiais na Várzea do Lago Grande de Curuai, Pará, Brasil
}

\author{
Marcelo Andrade AMORIM¹, Patrícia Florio MOREIRA-TURCQ², Bruno Jean TURCQ³, Renato Campello \\ CORDEIRO $^{4}$
}

\begin{abstract}
RESUMO
Este estudo tem por objetivo caracterizar os sedimentos superficiais de um sistema de Várzea do Rio Amazonas, quanto a sua granulometria e ao seu teor orgânico, assim como compreender a origem e a hidrodinâmica destes sedimentos. 51 amostras de sedimento superficial foram coletadas na Várzea do Lago Grande de Curuai, localizada na margem direita do Rio Amazonas à aproximadamente $850 \mathrm{~km}$ da foz. A granulometria, o teor em carbono orgânico e nitrogênio total, a razão entre o carbono e o nitrogênio $(\mathrm{C} / \mathrm{N})$, assim como o isótopo estável do carbono $\left(\delta^{13} \mathrm{C}\right)$ e do nitrogênio $\left(\delta^{15} \mathrm{~N}\right)$ foram utilisados para este fim. Este estudo colocou em evidência que os sedimentos da várzea são finos, caracterizados principalmente pela presença de silte (médio à fino), seguido de argila e tem como principal fonte o Rio Amazonas e a Formação Alter do Chão. A presença de areia é pequena e extremamente localizada, próxima as áreas de deságue dos igarapés de terra firme que representam sua maior fonte. O teor de matéria orgânica nestes sedimentos varia entre 1,5 à 37\% de carbono. Os resultados do isótopo do carbono $\left({ }^{13} \mathrm{C}\right)$ e da razão $\mathrm{C} / \mathrm{N}$ evidenciam a presença de matéria orgânica composta por diferentes fontes: material orgânico terrígeno, macrofítico, solos, material orgânico transportado pelo rio, e um componente fitoplanctônico.
\end{abstract}

PALAVRAS-CHAVE: Carbono, Origem da matéria orgânica, Granulometria, Hidrodinâmica, Várzeas.

\section{Source and deposition dynamics of superficial sediments in the "Várzea do Lago Grande de Curuai" floodplain, Pará, Brazil}

\begin{abstract}
The main objectives of this study were to characterize superficial sediments of an Amazonian floodplain system, by its size and organic content, and also to understand the local hydrodynamic and sources of these sediments. 51 samples of superficial sediment were collected in the floodplain "Várzea do Lago Grande de Curuai", located on the right bank of the Amazon River, approximately, $850 \mathrm{~km}$ from the estuary. The granulometry, the organic carbon and total nitrogen contents, the carbon and nitrogen ratio $(\mathrm{C} / \mathrm{N})$, as well as the isotope of carbon $\left(\delta^{13} \mathrm{C}\right)$ and nitrogen $\left(\delta^{15} \mathrm{~N}\right)$ were used. This study points out that the sediments of the Curuai floodplain are fine, characterized mainly by the presence of silt (medium to fine), followed by clays. The main sources of these sediments are the Amazon River followed by "Alter do Chão" formation. The presence of sand was extremely located and near the inflow areas of "terra firme" igarapés that are the main source. The organic matter contents ranged between $1.5 \%$ and $37 \%$ of carbon. On the other hand, the results of ${ }^{13} \mathrm{C}$ and $\mathrm{C} / \mathrm{N}$ ratio evidence the presence of an organic matter made up of different sources: flooding forest, macrofítes, soil, organic material carried by the River and a phytoplanctonic component.
\end{abstract}

KEYWORDS: Carbon, Organic matter sources, Granulometry, Hydrodynamics, Floodplains.

\footnotetext{
1 Departamento de Geoquímica, Universidade Federal Fluminense. Outeiro São João Batista s/nº $5^{\circ}$ andar, Centro, Niteroi,RJ-Brasil 24020-007 e-mail: marceloceano@yahoo.com.br

2 Institut de Recherche pour le Développement-LMTG-HYBAM Centre d'lle de France, 32 avenue Henri Varagnat, 93143 Bondy, France e-mail: patricia.turcq@ird.fr

3 Institut de Recherche pour le Développement., Centre d'lle de France, 32 avenue Henri Varagnat, 93143 Bondy, France e-mail: bruno.turcq@ird.fr

${ }^{4}$ Departamento de Geoquímica, Universidade Federal Fluminense Outeiro São João Batista s/nº $5^{\circ}$ andar, Centro, Niteroi,RJ-Brasil 24020-007 e-mail: rcampello@yahoo.com
} 


\section{INTRODUÇÃO}

Os ecossistemas aquáticos lacustres são ambientes deposicionais que apresentam em seus sedimentos registros dos processos que ocorreram "in situ" e em sua bacia de drenagem. A granulometria dos sedimentos é de grande interesse para compreendermos a hidrodinâmica dos lagos, principalmente, de lagos de várzea onde o transporte do material é fortemente influenciado pelas variações hidrológicas do rio. A caracterização do material orgânico sedimentar, presente nestes sistemas, é de suma importância e utilidade para se conhecer a origem e os processos a que estes ambientes estiveram submetidos em um passado recente (últimos cem anos) ou mais antigo (milhares de anos). Medidas complementares da composição molecular e isotópica da matéria orgânica podem produzir importantes indicadores de fonte e da natureza deste material em lagos (Meyers, 1994) e em grandes rios (Hedges et al., 1986). Diversos tipos de traçadores da matéria orgânica são utilizados para identificar as prováveis origens e os processos a que esta matéria esteve sujeita durante sua formação. Segundo Meyers \& Ishiwatary (1993) e Meyers (1994; 2003) a razão carbono/nitrogênio $(\mathrm{C} / \mathrm{N})$ é um dos marcadores mais confiáveis para indicação de fontes da matéria orgânica para um ecossistema. A matéria orgânica de origem autóctone na água, isto é, produzida principalmente pela comunidade planctônica local, tem razão molar $\mathrm{C} / \mathrm{N}$ entre 6 e 8 . Já as bactérias apresentam valores inferiores entre 4 e 5 . Valores de $\mathrm{C} / \mathrm{N}$ superiores a 20 são característicos da matéria orgânica terrestre, produzida principalmente por plantas superiores. Já os sedimentos em suspensão de grandes rios caracterizados por altos teores de material, como é o caso do Rio Amazonas, são caracterizados por um C/N de 10 (Hedges et al., 1986) próximo ao dos solos encontrados na Amazônia. Evidenciando que grande parte do material orgânico transportado pelo Amazonas tem sua origem na lavagem dos solos da sua bacia.

A composição do isótopo estável do carbono $\left(\delta^{13} \mathrm{C}\right)$ da matéria orgânica produzida por organismos fotossintéticos reflete a dinâmica da assimilação de carbono e a composição isotópica da fonte de carbono inorgânico. A diferença no $\delta^{13} \mathrm{C}$ entre matéria orgânica produzida por plantas terrestres e algas tem sido sucessivamente utilizada para traçar as fontes de distribuição da matéria orgânica no sedimento (GarcetteLepecq et al., 2000). Plantas que incorporam carbono $\mathrm{C}_{3}$, ou seja, plantas com menor presença de carbono na cadeia, apresentam valores de $\delta^{13} \mathrm{C}$ de aproximadamente $-20 \%$ de razão isotópica. Gramíneas, as quais têm necessidade de terem mais carbono em sua cadeia $\left(\mathrm{C}_{4}\right)$ apresentam uma razão isotópica entre aproximadamente -12 e -8 \%o. Segundo Meyers \& Ishiwatari (1993), valores de razão isotópica acima de $-20 \%$ podem indicar a formação da matéria orgânica por algas planctônicas tanto em ambiente lacustre quanto marinho.

Já o isótopo de nitrogênio $\left(\delta^{15} \mathrm{~N}\right)$ é utilizado para a identificação de processos, principalmente os de degradação ocorrendo no sistema. $\mathrm{O}$ valor de $\delta^{15} \mathrm{~N}$ de $\mathrm{NO}_{3}$ dissolvido, que é a forma mais comum de nitrogênio inorgânico dissolvido (DIN) nas águas usado por algas, é tipicamente entre 7-10\%o maior do que o $\mathrm{N}_{2}$ derivado da atmosfera, o qual possui um $\delta^{15} \mathrm{~N}$ de aproximadamente $0 \%$ e é a forma fixada pelas plantas terrestres (Meyers, 1994). A diferença isotópica entre estas duas fontes de nitrogênio é preservada no $\delta^{15} \mathrm{~N}$ da matéria orgânica das algas $\left(+8,5 \%\right.$ ) e por plantas $\mathrm{C}_{3}(+0,5 \% 0)$ (Peterson et al., 1987).

Os rios da Bacia Amazônica são acompanhados ao longo de seus cursos por planícies de inundação, compostas por lagos e florestas inundáveis (Junk, 1997), que afetam os processos de erosão, transporte, produção e sedimentação da matéria orgânica (Moreira-Turcq et al., 2004) e dos sedimentos (Maurice-Bourgoin, 2007) carreados pelos rios. Estes lagos são ambientes interessantes, do ponto de vista geoquímicosedimentar, pois são testemunhos dos processos que ocorrem atualmente e/ou que ocorreram no passado. Este estudo tem como objetivos caracterizar, com base no tamanho de seus grãos e no teor orgânico, os sedimentos superficiais de um sistema de várzea Amazônico, a Várzea do Lago Grande de Curuai, Pará, e determinar a origem desta matéria orgânica e a dinâmica destes sedimentos.

\section{ÁREA DE ESTUDO}

A várzea do Lago Grande de Curuai está localizada na margem sul do Rio Amazonas, próximo à cidade de Óbidos $850 \mathrm{~km}$ a montante da desembocadura deste no Oceano Atlântico. Esta várzea (Figura 1) é composta por diversos lagos de águas brancas, como o Lago Grande, Poção, Santa Ninha e Salé, e lagos de águas pretas, como o Curumucuri e Açaí. Esses lagos são interligados uns aos outros, e conectados ao Rio Amazonas por pequenos canais (igarapés) (Bonnet et al., 2007), com exceção do lago de águas pretas, Lago Açaí, que é um lago isolado e que apresenta somente um canal de ligação com o Rio Amazonas. Já o Lago Curumucuri apresenta um canal de ligação entre o Amazonas que se conecta também ao Lago do Salé, mas sem troca significativa de água entre os dois lagos, somente as águas do Lago Curumucuri, já diluídas com as águas do Amazonas, deságuam no Lago do Salé.

A variação anual do nível da água da várzea acompanha as variaçōes do Rio Amazonas (Bonnet et al., 2007). O nível máximo ocorre entre maio e junho e o mínimo é entre novembro e dezembro (Moreira-Turcq et al., 2004). A área inundável varia entre 1340 e $2000 \mathrm{~km}^{2}$ (Kosuth, 2002) de acordo com o período de vazante e de cheia e pode alcançar, durante anos de cheias extremas, até $3600 \mathrm{~km}^{2}$. 


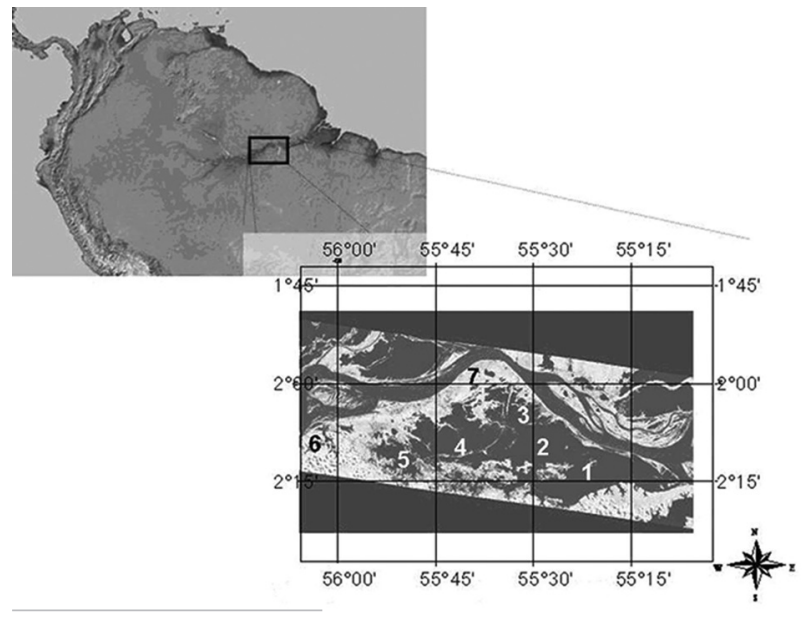

Figura 1 - Localização da Várzea do Lago Grande de Curuai e seus respectivos lagos: 1-Lago Grande; 2-Lago Grande do Poção; 3-Lago Santa Ninha; 4-Lago do Poção; 5-Lago do Salé; 6-Lago Curumucuri; 7-Lago Açai e 8-Rio Amazonas.

\section{MATERIAIS E MÉTODOS}

Foram coletadas 51 amostras de sedimento superficial ao longo de toda a várzea, com o objetivo de se obter a melhor caracterização possível dos sedimentos superficiais (Figure 2).

A coleta foi realizada durante duas campanhas de amostragem (novembro de 2003 e agosto de 2004). Os sedimentos foram coletados por meio de draga do tipo Eckman. Estas amostras foram armazenadas em pequenos frascos pré-lavados em laboratório com água destilada e solução de ácido clorídrico. Os parâmetros analisados nestas amostras foram granulometria, teor orgânico, e isótopos do carbono e nitrogênio.

A granulometria do sedimento foi medida com um Analisador de Partículas a Laser (CILAS modelo 1064) pelo

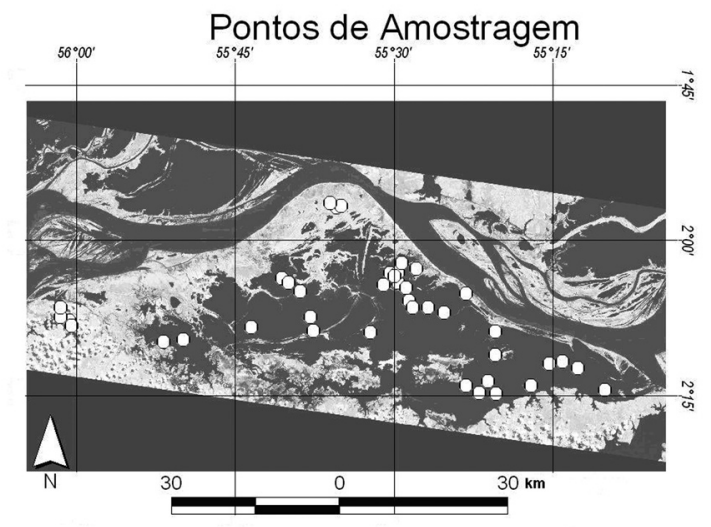

Figura 2 - Localização dos pontos de amostragem dos sedimentos superficiais na Várzea do Lago Grande de Curuai. método de difratometria a laser, o intervalo de detecção está compreendido entre 0,02 e $2000 \mu \mathrm{m}$. As amostras foram tratadas com peróxido de hidrogênio com a finalidade de eliminar o material orgânico, em seguida foi aplicado um dispersante e finalmente as amostras foram analisadas. Os dados gerados pelo equipamento foram analisados pelo programa GRADISTAT v. 4.0 - A Grain Size Distribution and Statistic Package for the Analysis of Unconsolidated Sediments by Sieving or Laser Granulometer, desenvolvido por Simon Blott (Dept of Geology, Royal Holloway, University of London). A partir deste programa foi obtida a divisão granulométrica de cada amostra, a distribuição amostral, e a classificação do material presente na amostra, representada pelo Triângulo de Shepard.

Para as análises de carbono e nitrogênio orgânico total dos sedimentos superficiais, as amostras foram secas à $40^{\circ} \mathrm{C}$, maceradas e pesadas (aproximadamente $10 \mathrm{mg}$ ), acondicionadas em cápsulas de estanho e analisadas na Universidade da Califórnia (UC Davies Stable Isotope Facility), nos Estados Unidos. A composição elementar foi obtida em um analisador elementar CHN.

Para a determinação da composição isotópica da matéria orgânica $\left(\delta^{13} \mathrm{Ce} \delta^{15} \mathrm{~N}\right)$, as amostras foram as mesmas utilizadas para a determinação da composição elementar e também analisadas no mesmo laboratório americano. As determinaçōes de $\delta^{13} \mathrm{C}$ e $\delta^{15} \mathrm{~N}$ foram obtidas em um espectrômetro de massa acoplado ao analisador elementar CHN.

\section{RESULTADOS E DISCUSSÃO}

\section{GRANULOMETRIA}

Os resultados da análise granulométrica dos sedimentos nos Lagos da Várzea de Curuai mostram, de maneira geral, predominância de sedimentos finos (silte e argila) no conjunto dos lagos. As amostras escolhidas para esta análise foram distribuídas ao longo de toda a superfície da várzea e permitiram uma boa caracterização do ambiente (Figura 3 e Tabela 1).

Na tabela 1 são apresentados os dados médios de argila, silte e areia (\%) e os percentuais mínimos e máximos encontrados em cada fração granulométrica para cada lago, assim como os valores médios de cada fração para o total da Várzea. Os maiores teores de argila foram encontrados nos lagos do Poção e Santa Ninha, provavelmente pelo fato de estarem em contato quase permanente com o Rio Amazonas e dos canais de conexão (igarapés) com o rio serem relativamente curtos $(<3,0$ $\mathrm{km})$. Com a chegada da água nos lagos (período de enchente), esta perde sua força, o que reduz também sua hidrodinâmica e favorece a precipitação do material fino transportado em suspensão. Este evento ocorre durante a vazante (MoreiraTurcq et al., 2004; Amorim, 2006; Maurice-Bourgoin et al., 


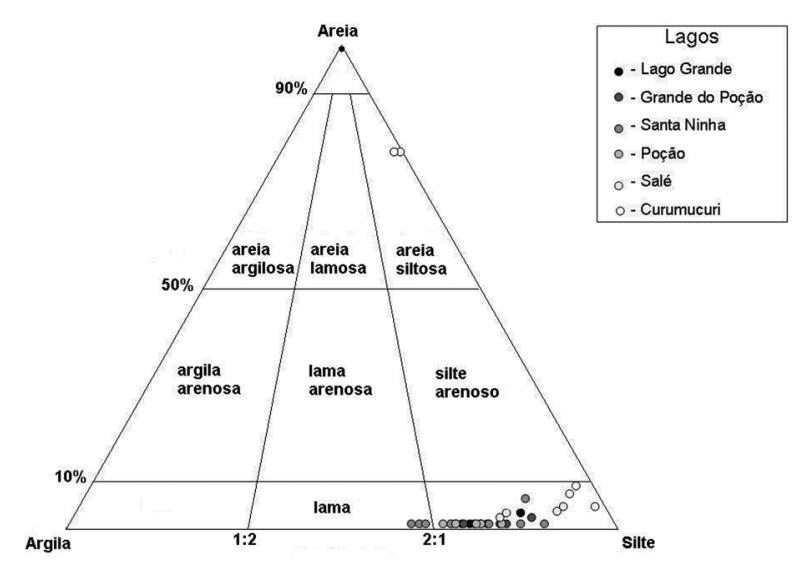

Figura 3 - Triângulo de Shepard apresentando as caracteristicas graulométricas dos sedimentos superficiais da Várzea do Lago Grande de Curuai.

Tabela I - Valores médios percentuais (com mínimos e máximos) das diferentes frações granulométricas dos sedimentos superficiais nos diversos lagos da Varzea do Lago Grande de Curuai e na própria Várzea.

\begin{tabular}{|c|c|c|c|c|}
\hline Lagos & $\mathrm{n}$ & $\begin{array}{c}\text { Argila (\%) } \\
(0,04-2 \mu \mathrm{m})\end{array}$ & $\begin{array}{c}\text { Silte (\%) } \\
(2-63 \mu \mathrm{m})\end{array}$ & $\begin{array}{c}\text { Areia }(\%) \\
(>63 \mu \mathrm{m})\end{array}$ \\
\hline Lago Grande & 10 & $\begin{array}{c}21,1 \\
(0,02-0,291)\end{array}$ & $\begin{array}{c}69,1 \\
(0,67-0,97)\end{array}$ & $\begin{array}{c}9,8 \\
(0,001-0,74)\end{array}$ \\
\hline $\begin{array}{l}\text { Lago Grande } \\
\text { do Poção }\end{array}$ & 2 & $\begin{array}{c}22,6 \\
(0,24-0,28)\end{array}$ & $\begin{array}{c}76,6 \\
(0,71-0,75)\end{array}$ & $\begin{array}{c}0,8 \\
(0,002-0,007)\end{array}$ \\
\hline $\begin{array}{l}\text { Lago Santa } \\
\text { Ninha }\end{array}$ & 7 & $\begin{array}{c}24,9 \\
(0,15-0,30)\end{array}$ & $\begin{array}{c}74,0 \\
(0,70-0,80)\end{array}$ & $\begin{array}{c}1,0 \\
(0,001-0,05)\end{array}$ \\
\hline Lago do Salé & 4 & $\begin{array}{c}16,75 \\
(0,15-0,18)\end{array}$ & $\begin{array}{c}78,9 \\
(0,70-0,80)\end{array}$ & $\begin{array}{c}4,4 \\
(0,04-0,11)\end{array}$ \\
\hline $\begin{array}{l}\text { Lago do } \\
\text { Poção }\end{array}$ & 6 & $\begin{array}{c}30,2 \\
(0,28-0,39)\end{array}$ & $\begin{array}{c}69,1 \\
(0,59-0,72)\end{array}$ & $\begin{array}{c}0,7 \\
(0,001-0,02)\end{array}$ \\
\hline $\begin{array}{l}\text { Lago } \\
\text { Curumucuri }\end{array}$ & 4 & $\begin{array}{c}6,0 \\
(0,01-10,6)\end{array}$ & $\begin{array}{c}57,0 \\
(0,002-0,87)\end{array}$ & $\begin{array}{c}37,8 \\
(0,03-0,99)\end{array}$ \\
\hline Lago Açaí & 1 & 12,9 & 84,1 & 3,0 \\
\hline $\begin{array}{l}\text { Valor médio } \\
\text { da Várzea }\end{array}$ & 34 & $\begin{array}{c}21,3 \\
(0,01-0,39)\end{array}$ & $\begin{array}{c}70,9 \\
(0,002-0,97)\end{array}$ & $\begin{array}{c}7,5 \\
(0,001-0,99)\end{array}$ \\
\hline
\end{tabular}

2007). O Rio Amazonas na proximidade da várzea do Lago Grande de Curuai tem profundidade aproximada de 60 metros, e o complexo de lagos têm em média, 4 à 6 metros. Durante o período de baixas águas o nível pode descer a 0,50 m (Bonnet et al., 2007). A água do Rio Amazonas, que entra no sistema da várzea tende a ser mais superficial, e em conseqüência transporta sedimentos mais finos como argila e silte. A maioria dos lagos apresenta característica siltosa, variando entre silte médio a fino consequencia da entrada de material em suspensão oriundo do Rio Amazonas e daquele erodido da formação Alter do Chão presente na margem sul da várzea.

Os menores teores de argila foram encontrados nos lagos de águas pretas, como o Curumucuri e o Açaí. Estes dois lagos são também caracterizados por baixos teores de material em suspensão (Amorim, 2006).

Os teores de areia são relativamente baixos em todos os lagos, nunca ultrapassando $10 \%$, com exceção do Lago Curumucuri, onde foi observado teores de até 34\%. Este lago é alimentado por um igarapé que drena a terra firme, no interior deste Igarapé o teor de areia do material superficial alcança $99 \%$ o que coloca em evidência os igarapés de terra firme como fonte de areia para o sistema. Os lagos que apresentaram os menores teores de areia $(<1 \%)$ e consequentemente os maiores de argila, são os Lagos Grande do Poção e o Lago do Poção. Esses são lagos de grandes dimensôes e se encontram no caminho de deságue da várzea para o Rio Amazonas.

O estudo granulométrico mostra igualmente relação entre a proximidade das florestas de terra firme e o aumento do teor de areia. É possível verificar também que os lagos mais próximos ao Rio Amazonas, sob influência direta deste apresentam, em geral, sedimentos mais finos (mais silte fino) do que os demais lagos no interior da várzea. $\mathrm{O}$ teor de material fino $(<63 \mu \mathrm{m})$ transportado pelo Rio Amazonas, em Óbidos, é de cerca de $95 \%$ (Perez, 2008). A presença predominante de material fino no Lago Açaí (águas pretas, mas não próximo a terra firme) também fortalece esta hipótese, pois este está em contato direto com o Rio Amazonas e sem contato com os demais lagos. A areia só é encontrada nos lagos sob influência direta dos aportes da terra firme, como o Lago do Salé e Grande, de águas brancas, e o Lago Curumucuri, de águas pretas.

\section{MATÉRIA ORGÂNICA}

O conteúdo de carbono orgânico (\%), nos sedimentos superficiais da Várzea do Lago Grande de Curuai variou entre 1,5 e $37 \%$ para a fração inferior a $63 \mu \mathrm{m}$ (Figura 4 e Tabela 2).

Os maiores valores (entre 21 e 37\%) foram encontrados nos lagos Santa Ninha, Grande e Poção próximos as suas margens onde durante o período de águas baixas, crescem os bancos de macrófitas (vegetais vasculares). Mas, de uma maneira geral, os lagos nos quais os teores de carbono foram os mais altos e homogeneamente distribuídos, foram os Lagos Açaí (média de 12,4\% de C) e Curumucuri, (6,7\% de C), ambos os lagos caracterizados por serem lagos de águas pretas (Figura 4).

Com relação à razão entre carbono e nitrogênio $(\mathrm{C} / \mathrm{N})$, que indica as possíveis fontes de matéria orgânica, os valores se apresentam bem homogêneos e baixos (Tabela 2), o que indica uma matéria orgânica enriquecida em nitrogênio. Estes valores de $\mathrm{C} / \mathrm{N}$ são, na sua maioria, inferiores aos dos sedimentos transportados pelo Amazonas (Figura 5) e indicam que outras fontes de matéria orgânica estão presentes na 
Tabela 2 - Média dos parâmetros geoquímicos orgânicos para cada lago da Várzea do Lago Grande de Curuai e média de todos os parâmetros para a Várzea. Valores mínimos e máximos de cada parâmetro em cada lago estudado.

\begin{tabular}{|c|c|c|c|c|c|c|}
\hline Lagos & $\mathrm{n}$ & $\% \mathrm{C}$ & $\% \mathrm{~N}$ & $\mathrm{C} / \mathrm{N}$ & $\delta^{15} \mathrm{~N}$ & $\delta^{13} \mathrm{C}$ \\
\hline Lago Grande & 12 & $\begin{array}{c}4,698 \\
(1,53-21,04)\end{array}$ & $\begin{array}{c}0,418 \\
(0,21-1,23)\end{array}$ & $\begin{array}{c}9,2 \\
(7,18-17,11)\end{array}$ & $\begin{array}{c}2,50 \\
(1,14-5,80)\end{array}$ & $\begin{array}{c}-26,33 \\
(-29,01 ;-23,31)\end{array}$ \\
\hline Lago Grande do Poção & 7 & $\begin{array}{c}2,516 \\
(1,65-5,87)\end{array}$ & $\begin{array}{c}0,315 \\
(0,23-0,71)\end{array}$ & $\begin{array}{c}7,9 \\
(7,01-8,34)\end{array}$ & $\begin{array}{c}3,08 \\
(2,54-3,73)\end{array}$ & $\begin{array}{c}-24,95 \\
(-25,85 ;-23,36)\end{array}$ \\
\hline Lago Santa Ninha & 9 & $\begin{array}{c}9,792 \\
(0,61-37,33)\end{array}$ & $\begin{array}{c}0,644 \\
(0,07-2,69)\end{array}$ & $\begin{array}{c}11,0 \\
(7,49-24,05)\end{array}$ & $\begin{array}{c}2,38 \\
(-1,23-4,97)\end{array}$ & $\begin{array}{c}-25,88 \\
(-29,45 ;-23,22)\end{array}$ \\
\hline Lago do Salé & 5 & $\begin{array}{c}2,752 \\
(1,89-3,61)\end{array}$ & $\begin{array}{c}0,305 \\
(0,21-0,40)\end{array}$ & $\begin{array}{c}9,1 \\
(8,99-10,42)\end{array}$ & $\begin{array}{c}2,72 \\
(2,17-3,26)\end{array}$ & $\begin{array}{c}-24,68 \\
(-26,54 ;-23,84)\end{array}$ \\
\hline Lago do Poção & 9 & $\begin{array}{c}6,613 \\
(1,12-30,75)\end{array}$ & $\begin{array}{c}0,549 \\
(0,16-2,01)\end{array}$ & $\begin{array}{c}8,9 \\
(7,08-15,23)\end{array}$ & $\begin{array}{c}2,98 \\
(1,41-4,69)\end{array}$ & $\begin{array}{c}-25,81 \\
(-29,22 ;-23,03)\end{array}$ \\
\hline Lago Curumucuri & 5 & $\begin{array}{c}6,707 \\
(3,73-9,16)\end{array}$ & $\begin{array}{c}0,693 \\
(0,38-0,92)\end{array}$ & $\begin{array}{c}9,7 \\
(9,37-9,95)\end{array}$ & $\begin{array}{c}1,45 \\
(0,80-1,95)\end{array}$ & $\begin{array}{c}-29,51 \\
(-31,01 ;-27,91)\end{array}$ \\
\hline Lago Açaí & 4 & $\begin{array}{c}12,408 \\
(11,78-13,38)\end{array}$ & $\begin{array}{c}1,344 \\
(1,30-1,40)\end{array}$ & $\begin{array}{c}9,2 \\
(8,92-9,52)\end{array}$ & $\begin{array}{c}0,58 \\
(0,42-0,87)\end{array}$ & $\begin{array}{c}-26,57 \\
(-27,05 ;-26,22)\end{array}$ \\
\hline Valor médio para a Várzea & 51 & $\begin{array}{c}6,29 \\
(0,61-37,33)\end{array}$ & $\begin{array}{c}0,55 \\
(0,07-2,69)\end{array}$ & $\begin{array}{c}9,33 \\
(7,01-24,05)\end{array}$ & $\begin{array}{c}2,42 \\
(-1,23-5,80)\end{array}$ & $\begin{array}{c}-26,13 \\
(-31,01 ;-23,03)\end{array}$ \\
\hline
\end{tabular}

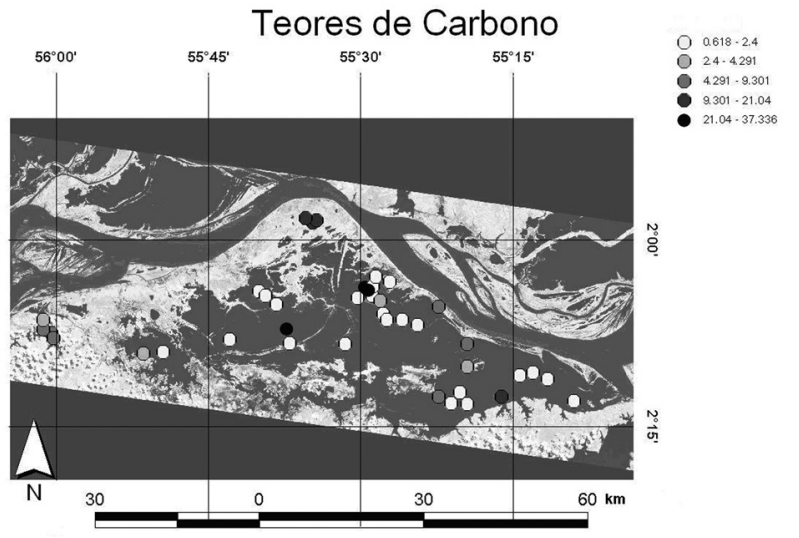

Figura 4 - Imagem da Várzea do Lago Grande de Curuai com os teores de carbono orgânico (\%) em função do peso total de sedimento nos diferentes pontos amostrados.

várzea. Raramente, a razão $\mathrm{C} / \mathrm{N}$ dos sedimentos superficiais foi superior à 10 , quando isto ocorreu $(\mathrm{C} / \mathrm{N}$ entre $15 \mathrm{e}$ 25) foi próximo as margens onde ocorrem os bancos de macrófitas. Os lagos que apresentam conexão direta com o Rio Amazonas, apresentam os valores médios dessa razão $\mathrm{C} / \mathrm{N}$ mais elevados, pois os bancos de macrófitas estão geralmente localizados próximos aos canais de ligação com o rio. Junk (1997) identificou como principais responsáveis pela produção orgânica nas várzeas Amazônicas: as florestas inundáveis, as macrófitas, o fitoplâncton e o perifiton. Na várzea do Lago Grande de Curuai as principais macrófitas presentes são: Paspalum repens e Echinochloa polystachya (Moreira-Turcq et al., submetido) ambas com razão $\mathrm{C} / \mathrm{N}$ superior à dos sedimentos superficiais e à dos sedimentos transportados pelo rio. Por outro lado, a Várzea de Curuai é caracterizada por alta biomassa fitoplanctônica nas suas águas (Moreira-Turcq et al. submetido), com a ocorrência de "blooms" (florescimentos)

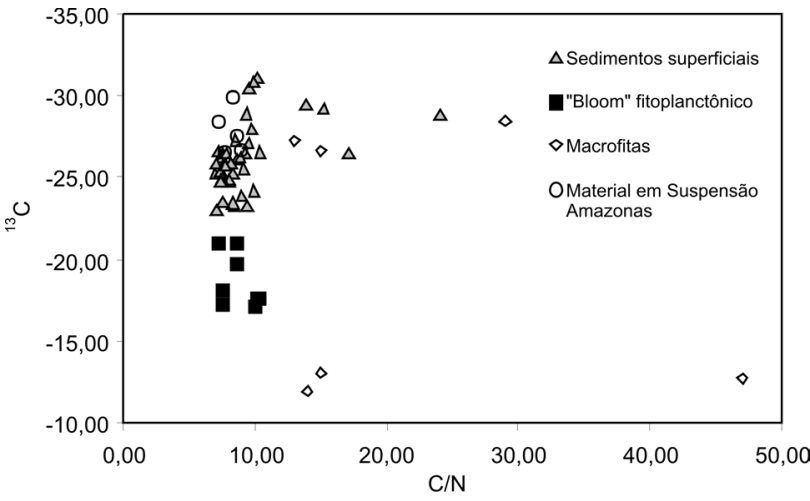

Figura 5 - Relação entre a razão $\mathrm{C} / \mathrm{N}$ e $\sigma^{13} \mathrm{C}$ dos sedimentos superficiais da Várzea do Lago Grande de Curuai, de "blooms" de fitoplâncton que ocorrem na várzea em diferentes períodos, das pricincipais macrófitas presentes e do material em suspensão transportado pelo Rio Amazonas (adaptado de Moreira-Turcq et al., submetido)

ao longo de todo o ciclo anual. A razão $\mathrm{C} / \mathrm{N}$ do fitoplâncton é caracterizada por baixos valores entre 6 e 8 (Meyers, 1994).

$\mathrm{O} \delta^{13} \mathrm{C}$ dos sedimentos superficiais, da várzea de Curuai, variou entre -31 e $-23 \%$ (Tabela 2). Os valores mais negativos $(-31 \%$ ) foram encontrados no Lago Curumucuri que é de águas pretas. Valores mais leves (cerca de -32\%o) também foram encontrados por outros autores (Lima da Costa, 2006) em sedimentos do Lago Acarabixi no Rio Negro. Os demais valores entre $-24,68$ e $-26,57 \%$ indicam mistura de fontes: fitoplanctônicas, macrofíticas e terrestres, esta última é incorporada a água devido aos processos de erosão dos solos da bacia de drenagem que posteriormente é transportada em suspensão pelas águas do Rio Amazonas e também pela bacia de drenagem da própria várzea.

Para comparar os resultados obtidos $\left(\delta^{13} \mathrm{C}\right.$ e da razão $\mathrm{C} / \mathrm{N}$ ) com outros da literatura em diferentes compartimentos 
e locais da Bacia Amazônica (Hedges et al., 1986; Hamilton \& Lewis, 1992; Quay et al., 1992; Martinelli et al., 2003), foram escolhidos como valor médio da composição isotópica $\delta^{13} \mathrm{C}$ dos sedimentos da várzea somente os dos lagos de águas brancas (Tabela 3), pois são os mais representativos, em termos de superfície, deste sistema. $\mathrm{O} \delta^{13} \mathrm{C}$ médio do material em suspensão presente no Rio Amazonas é de aproximadamente $-28,5 \%$ (Hedges et al., 1986). O sinal em $\delta^{13} \mathrm{C}$ do material em suspensão do Amazonas, que é uma das principais fontes para a várzea, é levemente mais negativo do que a maioria das amostras encontradas nos lagos de águas brancas na várzea. Isso indica que os sedimentos da várzea são uma mistura complexa de diferentes fontes. $\mathrm{O} \delta^{13} \mathrm{C}$ encontrado em vários "blooms" de fitoplâncton no interior da várzea (Moreira-Turcq et al., submetido), mostra valores bastante diferentes (entre -17,68\%o e -23\%o) daqueles propostos por Hamilton \& Lewis (1992) e por Martinelli et al. (2003), para várzeas do Orinoco e do Amazonas, respectivamente. Estes autores encontraram valores mais negativos, em torno de $-33 \%$, para o fitoplâncton. O que indica um baixo fracionamento do $\delta^{13} \mathrm{C}$ durante os "blooms" na Várzea de Curuai. A maioria dos dados de $\delta^{13} \mathrm{C}$ da várzea estão entre dois extremos (o material orgânico do Amazonas e os "blooms" fitoplânctonicos) indicando uma mistura de fontes de matéria orgânica no interior da mesma com um componente fitoplanctônico bastante importante e preservado visto o baixo $\mathrm{C} / \mathrm{N}$ (em torno de 7,5) e os altos valores de $\delta^{13} \mathrm{C}$ dos sedimentos. A componente macrofítica também está presente mas diluída visto que a principal macrófita (Echinochloa polystachya) apresenta um $\mathrm{C} / \mathrm{N}$ muito mais alto (47) do que o encontrado nos sedimentos.

Os resultados do $\delta^{15} \mathrm{~N}$ variaram entre -1 e $6 \%$ sendo que a maior parte está entre 1 e $4 \%$. O $\delta^{15} \mathrm{~N}$ é indicador dos processos que ocorrem durante a fotossíntese, das concentrações das diferentes espécies de nitrogênio assimiladas durante a fotossíntese assim como do seu fracionamento (Vuorio et al. 2006). Quando os valores são próximos a zero, indicam fixação direta do nitrogênio molecular $\left(\mathrm{N}_{2}\right)$ típico de algumas espécies de cianobactérias. $\mathrm{Na}$ tabela 2, pode-se observar que os lagos de águas pretas (Curumucuri e Açaí) apresentam valores inferiores ao dos de água branca. Os lagos na região central da Várzea, ou seja, os que recebem influência tanto do Amazonas quanto das regiōes de terra firma, e onde ocorrem preferencialmente os "blooms" fitoplanctônicos, como é o caso dos Lagos Grande do Poção e Poção, apresentam valores maiores de $\delta^{15} \mathrm{~N}$. A maioria das estaçôes situadas no meio dos lagos com valores mais altos (de até 5,80 ) indicam, provável produção primária in situ. As estações próximas ao Rio Amazonas com baixos valores de $\delta^{15} \mathrm{~N}$, em torno de $0 \%$, indicam provavelmente a presença de cyanobactérias.

\section{CONCLUSÕES}

Os sedimentos superficiais da Várzea do Lago Grande de Curuai, de um modo geral, são siltosos, variando entre silte médio a fino. Este material, mais fino, tem sua origem na erosão dos Andes (transportado pelo Rio Amazonas) e das rochas sedimentares da Formação Alter do Chão na parte sul da várzea. A presença de areia no sistema é restrita e localizada próximo a principal fonte que são os igarapés de terra firme presentes na margem sul da várzea.

Foi observado que, de maneira geral, são os lagos de águas pretas que possuem os teores mais elevados de material orgânico no sedimento. Isso se dá, principalmente, pelo fato destes apresentarem águas mais ácidas que tendem a preservar melhor o material orgânico e/ou pelo fato destes lagos serem caracterizados por baixos teores de material mineral em suspensão que poderia diluir o conteúdo orgânico do sedimento.

Nos lagos de águas brancas, os teores de matéria orgânica são variáveis e geralmente dependentes da proximidade do Rio Amazonas. Os mais próximos têm tendência a apresentarem menores concentrações de carbono orgânico do que os mais distantes do curso principal, isto está relacionado ao maior aporte de material mineral carreado pelo Rio Amazonas.

O material orgânico presente na várzea é conseqüência de processos de produção in situ (principalmente pelo fitoplâncton) e nas margens (pelas macrófitas), da decomposição deste material, do material presente nas florestas inundáveis e por último da diluição do material orgânico transportado pelo rio. Os baixos valores encontrados para a razão $\mathrm{C} / \mathrm{N}$, assim como os valores intermediários de $\delta^{13} \mathrm{C}$, indicam que os sedimentos superficiais são caracterizados por uma mistura de todas as fontes acima citadas. Ou seja, durante a permanência no

Tabela 3 - Valores de ${ }^{13} \mathrm{C}$ e da razão $\mathrm{C} / \mathrm{N}$ em diversos compartimentos do material orgânico da Amazônia e comparação com outros trabalhos em diferentes regiões.

\begin{tabular}{lllll}
\hline Trabalhos & Área de estudo & C/N & $\delta^{13} C$ & $n$ \\
\hline Hedges et al (1986) & Rio Amazonas, Brasil & 9 & $-28,3$ & 21 \\
Hamilton \& Lewis (1992) & Várzeas no Rio Orinoco, Venezuela & 7,67 & $-28,17$ & 15 \\
Amorim et al. (este trabalho) & Várzea do Lago Grande do Curuai & 9,33 & $-26,13$ & 41 \\
Moreira-Turcq et al. (submetido) & Várzea do Lago Grande do Curuai (florescimentos de fitoplâncton) & 6,19 & $-19,37$ & 7 \\
Meyers, 1994 & Grandes Lagos, Canadá & 16,4 & $-20,6$ & - \\
\hline
\end{tabular}


interior da várzea, o material orgânico original presente nas águas do rio é misturado com detritos de plantas vasculares, com o material húmico dos solos de áreas sazonalmente inundadas e com a matéria orgânica produzida in situ originária do fitoplancton, do perifiton e das macrófitas.

\section{AGRADECIMENTOS}

Este estudo faz parte de um projeto de Cooperação Internacional entre o CNPq e o IRD (Institut de Recherche pour le Développement - França) e é realizado pelo Programa Hybam. M.A. Amorim agradece à CAPES pela bolsa de mestrado.

\section{BIBLIOGRAFIA CITADA}

Amorim, M.A. 2006. Estudo da sedimentação recente na Várzea do Lago Grande de Curuai, Pará, Brasil. Dissertação de mestrado, Universidade Federal Fluminense, Niterói, RJ, 144pp.

Bonnet, M.P.; Barroux, G.; Martinez, J.M. ; Seyler, F.; Moreira-Turcq, P.; Cochonneau, G.; Melack, J.M.; Boaventura, G.; MauriceBourgoin, L.; León, J.G.; Roux, E.; Calmant, S.; Guyot, J.L.; Seyler, P. 2007. Flooding hydrology in an Amazonian floodplain lake (Lago Grande de Curuaí). Journal of Hydrology, 349(1-2): 18-30.

Garcette-Lepecq, A.; Derenne, S.; Largeau C.; Bouloubassi, I.; Saliot A. 2000. Origin and formation pathway of kerogen-like organic matter in recent sediments off the Danube delta (northwestern Black Sea). Organic Geochemistry, 31: 1663-1683.

Hamilton, S.K.; Lewis, W.M. 1992, Stable carbon and nitrogen isotopes in algae and detritus from the Orinoco River floodplain, Venezuela. Geochimica \& Cosmochimica Acta, 56: 4237-4246.

Hedges, J.I.; Clark, W.A; Quay, P.D.; Richey, J.E.; Devol, A.; Santos, U. 1986a, Composition and fluxes of particulate organic material in the Amazon River. Limnology and Oceanography, 31(4): 717-738.

Junk, W. J. 1997. General aspects of floodplain ecology with special reference to amazonian floodplains. In: W.J. Junk (ed.) The Central Amazon floodplain: ecology of a pulsing system, Springer, Berlin: 3-20 pp.

Lima da Costa, R. 2006. Paleohidrologia do Lago Acarabixi, médio Rio Negro, Am, durante o Holoceno. Dissertação de mestrado, Universidade Federal Fluminense, Niterói, RJ, 101 pp.

Kosuth, P. 2002. A case study of floodplains dynamics: dynamics, water balance, sediment balance of the Várzea of Lago Grande de Curuaí. In: $2^{\text {nd }}$ LBA (Large Scale Biosphere Atmosphere), Scientific Conference, Manaus, July 2002, 7-10pp.
Maurice-Bourgoin, L..; Bonnet, M.-P.; Martinez, J.-M.; Kosuth, P.; Cochonneau;, G.; Moreira-Turcq, P.; Guyot , J.-L.; Vauchel, P.; Filizola, N.; Seyler, P. 2007. Temporal dynamics of water and sediment exchanges between the Curuaí floodplain and the Amazon River, Brazil. Journal of Hydrology, 335: 140-156.

Martinelli, L.A.; Victoria, R.L.; Camargo, P.B.de; Picollo, M.C., Mertes, L.; Richey, J.E.; Devol, A.H.; Forsberg, B.R. 2003, Inland variability of carbon-nitrogen concentrations and $\delta^{13} \mathrm{C}$ in Amazon floodplain (varzea) vegetation and sediment. Hydrological Processes, 17: 1219-1229.

Meyers, P. 1994. A.preservation of elemental and isotopic source identification of sedimentary organic matter. Chemical Geology, 114: 289-302.

Meyers, P.A. 2003. Applications of organic geochemistry to paleolimnological reconstructions: a summary of exemples from the Laurentian Great Lakes. Organic Geochemistry, 34: 261-289.

Meyers, P.; Ishiwatary R. 1993. Lacustrine organic geochemistry - an overview of indicators of organic matter sources and diagenesis in lake sediments. Organic Geochemistry. 20(7): 867-900.

Moreira-Turcq, P.; Jouanneau, J. M.; Turcq, B.; Seyler, P.; Weber, O.; Guyot, J. L. 2004. Carbon sedimentation at Lago Grande de Curuai, a floodplain lake in the low Amazon region: insights into sedimentation rates. Palaeogeography, Palaeoclimatology, Palaeoecology, 214(1-2): 27-40.

Moreira-Turcq, P.; Amorim, M.; Bernardes, M.; Bonnet, M.P.; Maurice, L.; Perez, M.; Seyler. P. 2008. Impact of floodplains on the nature, composition and age of particulate organic matter transported by the Amazon River. Global Biogeochemical Cycles (submetido).

Peterson B. J. ; Howarth R. W.; Garrit R.H. 1987. Multiple stable isotopes used to trace the flow of organic matter in estuarin food webs. Science, 227: 1361-1363.

Perez, M. A.P. 2008. Biogeoquímica da Várzea do Lago Grande de Curuai, Rio Amazonas, Pará, Brasil: caracterização, origem, ciclagem e destino do material orgânico e inorgânico. Tese de Doutorado, Departamento de Geoquímica, Universidade Federal Fluminense, Niterói, Brasil. 274pp.

Quay, P.D.,;Wilbur, D.O.; Richey, J.E.; Hedges, J.I.; Devol, A.H.; Victoria, R. 1992, Carbon cycling in the Amazon River: implications from the ${ }^{13} \mathrm{C}$ compositions of particles and solutes. Limnology and Oceanography, 37(4): 857-871.

Vuorio, K; Meili, M.; Sarvala, J. 2006. Taxon-specific variation in the stable isotopic signatures $\left(\delta^{13} \mathrm{C}\right.$ and $\left.\delta^{15} \mathrm{~N}\right)$ of lake phytoplankton. Freshwater biology, 51: 807-822.

Recebido em 16/06/2008

Aceito em 07/10/2008 
